\title{
Inflammatory pseudotumour of the testis
}

\author{
Ajith Lamahewage ${ }^{1}$, NG Ranawaka ${ }^{2}$, Nalitha N Wijesundere $^{3}$ \\ ${ }^{\prime}$ Senior Lecturer, ${ }^{2}$ Lecturer, Department of Pathology, Faculty of Medicine, University of Ruhuna, \\ Galle. ${ }^{3}$ Consultant Surgeon, Base Hospital, Balapitiya.
}

\section{Introduction}

Inflammatory pseudotumour is a tumour like lesion characterized histologically by fascicles of plump spindle shaped cells in a background of chronic inflammatory cells, predominantly plasma cells. Inflammatory pseudotumour occurs in a wide variety of somatic tissue and visceral organs, including the lung, liver, thyroid and many other organs. Inflammatory pseudotumour of the testis is a reactive nonneoplastic lesion that may mimic a neoplasm. We describe here the clinical and histological findings of inflammatory pseudotumour in the testis in an adult.

\section{Case Report}

A 70 year-old man was referred to the surgical clinic for a lump in the right testis. It had been present for more than one month and has not responded to antibiotics. Physical examination revealed a firm lump in the right testis. Ultrasound scanning of the scrotum revealed a neoplasm measuring $3 \times 2 \times 2 \mathrm{~cm}$ at the lower pole of the right testis. Right orchidectomy was done and the specimen sent for histology.

The specimen consisted of testis with a part of the spermatic cord. Serial sectioning of the specimen revealed a white gray lesion measuring $3 \times 2.5 \times 2$ $\mathrm{cm}$ partially encircling the testis extending from the lower pole to the upper pole.

Histological sections showed a lesion composed of fascicles of plump spindle shaped cells with a dense infiltrate of inflammatory cells comprising lymphocytes, plasma cells and histiocytes (Figure 1). No cellular pleomorphism or mitoses were noted. The adjacent testicular tissue and the spermatic cord were morphologically normal.



Figure 1 - Histological section of the testicular tumour

\section{Discussion}

Inflammatory pseudotumour of the testis is very rare and to our knowledge, was not reported previously in Sri Lanka. The cause of inflammatory pseudotumour remains unknown. Histological appearance of inflammatory pseudotumour of the testis is similar to that of inflammatory pseudotumour of other organs.

The proportion of spindle cells, foam cells, lymphocytes and plasma cells is highly variable. These spindle cells are fibro-histiocytic in nature. The cytological features of inflammatory pseudotumour have been described rarely. It is generally accepted that definite cytological diagnosis of inflammatory pseudotumour cannot be made by FNAC because the predominant cell proliferation is nonspecific.

Treatment is complete surgical resection which is curative.

\section{References}

1. AWH Shek, PC Wu, N Samman. Inflammatory pseudotumour of the mouth and maxilla. Journal of Clinical Pathology, 1996: 49(2): 164-7.

2. JY Ro, M Amin, AA Suhin, AG Ayala. Tumours and tumouress conditions of the male genital tract. In: Christopher DM Fletcher. Diagnostic Histopathology of Tumours, Churchill Livingstone, $2^{\text {nd }}$ Edition; Vol 1: $2000 ; 813$. 